\title{
The Incidence of Glutamic Acid Decarboxylase Autoantibodies and its Association With Clinical Features in Pregnant Women With Gestational Diabetes Mellitus
}

\author{
Malihe Mohammadi ${ }^{*}$, Seyedeh Solmaz Moosavi ${ }^{1}$ \\ ${ }^{1}$ Department of Biology, Faculty of Basic Sciences, University of Sistan and Baluchestan, Zahedan, Iran
}

\author{
*Correspondence to \\ Malihe Mohammadi, \\ Tel \& Fax: +985433446565 \\ Email: \\ mmohammadi@science.usb.ac.ir
}

Received December 20, 2018 Accepted March 17, 2019 Published online June 30, 2019

\begin{abstract}
Introduction: The association between the incidence of glutamic acid decarboxylase antibodies (GADAs) and risk of diabetes in pregnant women is controversial. Here, our aim was to investigate the incidence and clinical relevance of GADA and its association with development of post-delivery diabetes in women with gestational diabetes mellitus (GDM).

Methods: This cohort study was conducted in Torbat-e Heydarieh (Khorasan Razavi, Iran) from October 2015 to March 2017. A total of 147 pregnant women with GDM were included in case group. The control group consisted of 147 healthy controls. A GAD diagnostic kit (Diametra Co., Italy) was used for diagnosis of GADA. The history of insulin therapy and the development of diabetes one year after delivery were investigated.

Results: Of 147 pregnant women with GDM, $9(6.1 \%)$ had GADA in their sera. 14.3\% (21 out of 147 ) of women with GDM had history of insulin therapy. $33.3 \%$ (7 of 21 ) of women who had received insulin developed diabetes one year after delivery. Type 1 and type 2 diabetes were observed in, respectively, $1(0.7 \%)$ and 7 (4.8\%) of women with GDM at one year after delivery. At one year after delivery, no women in GADA negative women was diagnosed with type 1 diabetes. However, type 2 diabetes was observed in $2.9 \%$ of GADA negative pregnant women. Type 1 and type 2 diabetes were also noticed in, respectively, $11.1 \%$ and $33.3 \%$ of GADA positive mothers at one year after delivery.

Conclusion: The prevalence of GADA was $6.1 \%$ in diabetic pregnant women. The GADA positivity and history of insulin therapy during pregnancy were significant risk factors for diabetes at one year after delivery. In addition, development of type 1 diabetes was higher in GADA positive pregnant women with GDM than GADA negative women.

Keywords: Glutamic acid decarboxylase antibodies, Prevalence, Gestational diabetes mellitus; Diabetes mellitus
\end{abstract}

Please cite this article as follows: Mohammadi M, Moosavi SS. The incidence of glutamic acid decarboxylase autoantibodies and its association with clinical features in pregnant women with gestational diabetes mellitus. Int J Basic Sci Med. 2019;4(2):5660. doi:10.15171/ ijbms.2019.12.

\section{Introduction}

Gestational diabetes mellitus (GDM) may be diagnosed in pregnant women and is defined as any degree of glucose intolerance. ${ }^{1}$ GDM has been estimated to affect $1 \%-14 \%$ of pregnancies. ${ }^{2-4}$ Recently, the incidence of GDM has been reported to be $4.9 \%$ in Gorgan, Iran. ${ }^{5}$ In a systematic review and meta-analysis, $3.41 \%$ of Iranian pregnant women were reported to have GDM. ${ }^{6}$ GDM is a risk factor for pregnancy complications, ${ }^{4,7}$ particularly type 1 and type 2 diabetes. ${ }^{8}$ The reported global incidence of GDM varies from $2.6 \%$ to $70 \%{ }^{9}$ Although GDM and type 2 diabetes are clinically related conditions, a proportion of pregnant women with GDM show immune autoantibodies against pancreatic $\beta$-cell. ${ }^{10,11}$ The process of betacell destruction marked by the production of anti-islet autoantibodies is one of the most important features of type 1 diabetes. ${ }^{12}$ Therefore, the presence of these antibodies in some diabetic pregnant women indicate immune process of $\beta$-cell destruction.

The glutamic acid decarboxylase

(C) 2019 The Author(s); Published by Zabol University of Medical Sciences. This is an open-access article distributed under the terms of the Creative Commons Attribution License (http://creativecommons.org/licenses/by/4.0), which permits unrestricted use, distribution, and reproduction in any medium, provided the original work is properly cited. 
autoantibody (GADA) is the most frequent autoantibody in women with GDM, ${ }^{13}$ but autoantibodies against insulin (IAA), tyrosine phosphatase antibodies (IA2A) ${ }^{13,14}$ and recently zinc transporter $8(\mathrm{ZnT} 8)^{15}$ have also been reported during gestational diabetes. GDM complicated with GADA positivity is a prominent risk factor for type 1 diabetes during post delivery period. ${ }^{14,16,17}$ GADA antibodies have been suggested as highly sensitive predictors of type 1 diabetes. ${ }^{2,15,18}$ In addition, these women need insulin therapy during pregnancy more frequently. ${ }^{13,19,20} \mathrm{C}$-peptide is another marker in autoimmune diabetic patients. C-peptide is secreted in equimolar concentration with insulin concentration and its half-life is higher than insulin's. Hence, determination of C-peptide level is useful to quantify insulin and therefore to evaluate $\beta$-cell function. ${ }^{21}$ However, the incidence of GADA in Iranian pregnant women with GDM and its association with the development of postdelivery diabetes are unknown. Therefore, this study was carried out to investigate the incidence of GADA in Iranian pregnant women. The association between GADA positivity and the risk of post-delivery type 1 and type 2 diabetes at one-year post delivery period was also investigated.

\section{Materials and Methods}

\section{Participants}

We enrolled 147 women with GDM and 147 healthy, agematched women as case and control groups, respectively. No history of GDM, type 1 diabetes, and type 2 diabetes were observed in control group. This study was carried out in the 9th Dey Hospital and primary health care centers in Torbat-e Heydarieh (Khorasan Razavi province, Iran) from October 2015 to March 2017. An informed written consent to participate in the study was obtained from the participants.

\section{Sample Size}

In this study, sampling was done systematically. The study population (n: 735) consisted of eligible women referring to the studied hospital and health care centers, one fifth of whom (n: 147) were randomly selected based on the Krejcie and Morgan Table.

\section{Patient Recruitment and Screening}

The participants first underwent the $50 \mathrm{~g}$ glucose challenge test (GCT) according to the universal two-step GDM screening program. The challenge test was carried out within the 24th-28th weeks of gestation except for those older than 35 years old and those with family history of diabetes or GDM in whom the challenge test was conducted within the 14th-18th weeks of gestation. Women with fasting blood sugar (FBS) of $>130 \mathrm{mg} / \mathrm{dL}$ after 1 hour were retested by the $100 \mathrm{~g} 3$ hours oral glucose tolerance test (OGTT) following overnight fasting. GDM diagnosis was made according to the criteria of Carpenter and Coustan. ${ }^{22}$ GDM was diagnosed if at least two out of the following four criteria were met: FBS $>95 \mathrm{mg} / \mathrm{dL}$ and blood glucose $>180 \mathrm{mg} / \mathrm{dL},>155 \mathrm{mg} / \mathrm{dL}$ and $>140 \mathrm{mg} / \mathrm{dL}$ at 1,2 , and 3 hours post challenge test, respectively. ${ }^{22}$ The OGTT was repeated in women who fulfilled one of the above-mentioned criteria after 1 month.

\section{Autoantibody Detection}

The women diagnosed with GDM were further evaluated for the presence of GADA. Blood samples were collected during the 14th-41th weeks of pregnancy. The women should not be under insulin therapy during blood samples collection. Serum samples were separated by centrifugation and frozen at $-80^{\circ} \mathrm{C}$. GADA was scrutinized using the Isletest GAD diagnostic kit (Diametra Co., Italy).

Measurement of C-Peptide Levels

C-peptide level was measured using a specific ELISA kit (IBL, USA) to the nearest $0.064 \mathrm{ng} / \mathrm{mL}$. C-peptide concentration was determined using a standard curve obtained from known values of standard absorbance at $450 \mathrm{~nm}$.

\section{Study Procedure}

History of diabetes in family or GDM in previous pregnancies, body mass index (BMI), history of insulin therapy, the results of OGTT and serum C peptide level measurement, birth weight, and history of caesarean section in GADA positive and negative women and controls.

\section{Follow-up}

After delivery, the frequency of diabetes was determined using 75-g OGTT. Normal glucose tolerance (NGT) was considered to be 2-hour post-glucose level of $<140$ $\mathrm{mg} / \mathrm{dL}$. Impaired glucose tolerance (IGT) was defined as FBS of 100-125 mg/dL and 2-hour post glucose level of $140-199 \mathrm{mg} / \mathrm{dL}$. Diabetes mellitus was considered as FBS of $\geq 126 \mathrm{mg} / \mathrm{dL}$ or 2 -hour post glucose level of $\geq 200$ $\mathrm{mg} / \mathrm{dL}$. The women with positive GADA result were variably followed up for 6-12 months post-delivery. The diabetes classification was done using the guideline of the American Diabetes Association. ${ }^{23}$

\section{Statistical Analysis}

The SPSS 16.0 software was used to perform statistical analyses. Data was presented as mean \pm SD and percentage. The independent samples student $t$ test was used to investigate the significance of difference in the mean values of quantitative variables among GADA positive, GADA negative and healthy women. $P<0.05$ was considered statistical significance level. 


\section{Results}

In GDM group, 6.1\% (9 of 147) were positive for GADA. The mean age at enrollment was $30.66 \pm 5.52$ and 31.26 \pm 5.7 years old in the GADA positive women with GDM and controls, respectively. There was no significant difference in mean age, BMI, family history of diabetes, mean C-peptide level and number of caesarean sections between GADA positive and GADA negative women. Nevertheless, a significant difference was observed between these 2 groups in terms of birth weight (3.16 \pm 0.29 vs. $3.48 \pm 0.35, P=0.01)$. Among 147 women with GDM, type 1 and type 2 diabetes were diagnosed in, respectively, $1(0.7 \%)$ and 7 (4.8\%) individuals after delivery. The only women who developed type 1 diabetes and $42.8 \%$ (3 of 7 ) of those with type 2 diabetes were positive for GADA. Results regarding different variables studied in GADA positive and GADA negative participants are summarized in Table 1.

\section{Insulin Therapy for GDM}

Insulin had been administrated to $14.3 \%$ (21 of 147) of the women with GDM. Among these women, GADA positivity was detected in $5(23.8 \%)$ individuals. A higher proportion of GADA positive women with GDM required insulin therapy $(55.6 \%)$ in comparison with GADA negative $(11.6 \%)$ ones. The only woman who needed insulin after delivery developed type 1 diabetes, and 6 out of $7(85.7 \%)$ women who were diagnosed with type 2 diabetes had history of insulin therapy during pregnancy.

Follow-up

At follow-up (during 1 year after childbirth) 44.4\% (4 out of 9) of women who were GADA positive developed diabetes compared with $2.9 \%$ of GADA negative ones. Type 2 diabetes was observed in 4 out of 138 GADA negative women, but only one GADA positive woman with GDM developed type 1 diabetes (Table 2).

\section{Discussion}

GDM is estimated to affect $1 \%-14 \%$ of pregnant women across the globe and its prevalence has increased during the last two decades. ${ }^{2,4}$ If GDM remains uncontrolled, it can cause numerous complications for both mother and fetus. Therefore, early detection and management of GDM are critical for preventing related complications. In addition, women diagnosed with GDM are at higher risk of developing type 1 and type 2 diabetes later in life.,13,16 One of the strongest predictors of type 1 diabetes after delivery in women with GDM is serum GADA level. The prevalence of GADA positivity in women with GDM has been reported to range from $0 \%$ to $38 \%$ in previous studies. ${ }^{13,20}$ The incidence of GADA positivity was $6.1 \%$ in our study, which is in line with previous reports. ${ }^{2,13}$

Comparison of baseline specifications of GADA positive and GADA negative pregnant women revealed no significant difference in age, BMI, family history of diabetes, number of caesarean sections and C-peptide level between the two groups. This result is similar to the result of studies in Korea ${ }^{20}$ and Sweden. ${ }^{2}$ Our results also showed significant differences in birth weight between GADA positive and GADA negative pregnant women $(P=0.01)$. However, the clinical causes of the relationship observed in our study are unknown, and more research is needed in this regard. An association is likely to exist between

Table 1. Characteristics of GADA-Positive and GADA- Negative Pregnant Women

\begin{tabular}{|c|c|c|c|}
\hline Characteristics & $\begin{array}{l}\text { GADA-Positive Women With } \\
\text { GDM }\end{array}$ & $\begin{array}{c}\text { GADA-Negative Women With } \\
\text { GDM }\end{array}$ & $P$ Value \\
\hline Number & $9(6.1 \%)$ & $138(93.9 \%)$ & NS \\
\hline Age pregnancy (years) ${ }^{\mathrm{a}}$ & $30.66 \pm 5.52$ & $31.26 \pm 5.7$ & 0.766 \\
\hline Pregnancy BMI $\left(\mathrm{kg} / \mathrm{m}^{2}\right)^{\mathrm{b}}$ & $24.8 \pm 1.49$ & $25.9 \pm 2.03$ & 0.105 \\
\hline Family history of diabetes $(\%)_{c}$ & $5(55.6 \%)$ & $73(52.9 \%)$ & NS \\
\hline Gestational diabetes mellitus during previous pregnancy (pregnancies) & 2 of $5(40 \%)$ & 53 of $115(46.1 \%)$ & NS \\
\hline Fasting oral glucose tolerance test value during pregnancy $(\mathrm{mg} / \mathrm{dL})^{\mathrm{d}}$ & $101.33 \pm 3.7$ & $99.78 \pm 4.48$ & 0.313 \\
\hline 1-h plasma glucose $(\mathrm{mg} / \mathrm{dL})$ & $189.33 \pm 2.39$ & $188.35 \pm 5.237$ & 0.577 \\
\hline 2-h plasma glucose (mg/dL) & $165.22 \pm 6.97$ & $164.03 \pm 5.94$ & 0.565 \\
\hline 3-h plasma glucose $(\mathrm{mg} / \mathrm{dL})$ & $151.22 \pm 5.04$ & $149.3 \pm 5.68$ & 0.395 \\
\hline Insulin therapy during pregnancy & $5(55.6 \%)$ & $16(11.6 \%)$ & NS \\
\hline Insulin therapy after pregnancy & $1(11.1 \%)$ & - & NS \\
\hline Mean C-peptide level (ng/mL) & $1.22 \pm 0.34$ & $1.45 \pm 0.54$ & 0.201 \\
\hline Caesarean section & $3(33.3 \%)$ & $36(26.1 \%)$ & NS \\
\hline Birth weight (g) & $3.16 \pm 0.29$ & $3.48 \pm 0.35$ & 0.010 \\
\hline
\end{tabular}

Abbreviations: GADA, glutamic acid decarboxylase antibody; BMI, nody mass index.

Data are median or number (\%).

${ }^{a}$ Age at blood sample collection during pregnancy; ${ }^{\mathrm{b}} \mathrm{BMI}$ was measured at the first trimester; ${ }^{\mathrm{C}}$ Family history of any types of diabetes among first or seconddegree relatives; ${ }^{d}$ During $24-28$ weeks of pregnancy. 
Table 2. The Development of Diabetes Mellitus in GADA-Positive and GADA-Negative Women After Delivery

\begin{tabular}{lccl}
\hline & GADA(+) & GADA(-) & $\boldsymbol{P}$ value \\
\hline Number & 9 & 138 & \\
Type 1 diabetes & $1(11.1 \%)$ & 0 & NS \\
Type 2 diabetes & $3(33.3 \%)$ & $4(2.9 \%)$ & NS \\
\hline
\end{tabular}

GADA positivity and insulin therapy during pregnancy. Among GADA positive women, 55.6\% (5 of 9) individuals and among GADA negative, $11.6 \%$ (16 of 138) ones used insulin therapy. At one year after delivery, no women in the GADA negative group needed insulin, whereas one woman with positive GADA during pregnancy who later developed type 1 diabetes needed insulin after delivery. All of the GADA positive women who developed type 2 diabetes after delivery (n: 3 ) had previously used insulin therapy while 3 of 4 GADA negative woman with GDM that were diagnosed with type 2 diabetes used insulin during pregnancy. This finding indicated that there may be an association between insulin therapy during pregnancy and development of diabetes after delivery. This, however, should be further investigated in future studies. Yu et al in Korea ${ }^{20}$ and Dereke et al in Sweden ${ }^{15}$ found that comparatively higher number of women with GDM and GADA positivity needed insulin therapy than those with GADA negativity.

In our study, no women in control group developed type 1 diabetes while $2.9 \%$ of these women were diagnosed with type 2 diabetes after delivery. These data confirmed that circulating autoantibodies during pregnancy in women with GDM could be a prominent risk factor for type 1 diabetes. However, the strength of our study was relatively low due to the relatively small sample size that can affect the results. Furthermore, there have been reports on the presence of other autoantibodies such as IA-2A, ZnT8 and IAA in GDM which could serve as predictors of autoimmunity in women with this disease. In fact, the presence of multiple antibodies has been shown to increase the risk of type 1 diabetes after delivery. ${ }^{24}$ Therefore all the mentioned autoantibodies should be measured in the screening process.

Some studies have shown that a significant proportion of women who are autoantibody positive during pregnancy develop diabetes few years after childbirth. ${ }^{2,3,20}$ In one study, about $42 \%$ of the GADA positive women who developed diabetes at follow-up were diagnosed with diabetes within 6 months, 50\% within 1 year, and nearly $83 \%$ within 4 years. Even two cases developed type 1 diabetes 5 and 8 years after delivery. ${ }^{2}$ In this study we followed up patients for one year after delivery, and therefore the frequency of women with diabetes may increase after the longer follow-up(s).

\section{Conclusion}

The incidence of GADA in pregnant women with GDM and its association with post-delivery diabetes were demonstrated for first time in Iran in the present study. Our findings revealed that GADA positivity increased the risk of both type 1 and type 2 diabetes at one year after delivery. It is therefore recommended to screen autoantibodies in women with GDM after delivery to detect women at risk early. To generalize the results of this study and use GADA as markers for gestational diabetes, systematic review and meta-analyses should be carried out to include larger sample size and different ethnicities across Iran.

\section{Competing Interests}

We have no conflict of interest.

\section{Ethical Approval}

All the procedures performed were approved by an institutional ethics committee (Torbat-e Heydarieh University of Medical Sciences, Iran).

\section{Acknowledgments}

We gratefully acknowledge the assistance of Monireh Mohammadi in Muslim Ibn-e-Aqil Medical Center, Torbat-e Heydarieh, Iran and the funding of University of Sistan and Baluchistan for this research project.

\section{References}

1. Galtier F. Definition, epidemiology, risk factors. Diabetes Metab. 2010;36(6 Pt 2):628-651. doi:10.1016/j. diabet.2010.11.014

2. Nilsson C, Ursing D, Törn C, Aberg A, Landin-Olsson M. Presence of GAD antibodies during gestational diabetes mellitus predicts type 1 diabetes. Diabetes Care. 2007;30(8):1968-1971. doi:10.2337/dc07-0157

3. Murgia C, Orrù M, Portoghese E, et al. Autoimmunity in gestational diabetes mellitus in Sardinia: a preliminary case-control report. Reprod Biol Endocrinol. 2008;6:24. doi:10.1186/1477-7827-6-24

4. Bentley-Lewis R. Gestational diabetes mellitus: an opportunity of a lifetime. Lancet. 2009;373(9677):17381740. doi:10.1016/s0140-6736(09)60958-2

5. Mohammadzadeh F, Eshghinia S, Vakili MA. The prevalence of gestational diabetes mellitus and its related risk factors in Gorgan, north of Iran. Selective or universal screening test is cost-effective? Int J Diabetes Dev Ctries. 2015;35(3):225-229. doi:10.1007/s13410-014-0209-8

6. Jafari-Shobeiri M, Ghojazadeh M, Azami-Aghdash S, et al. Prevalence and risk factors of gestational diabetes in Iran: a systematic review and meta-analysis. Iran J Public Health. 2015;44(8):1036-1044

7. Nguyen CL, Pham NM, Binns CW, Duong DV, Lee AH. Prevalence of gestational diabetes mellitus in eastern and southeastern Asia: a systematic review and meta-analysis. J Diabetes Res. 2018;2018:6536974. doi:10.1155/2018/6536974

8. Mishra S, Rao CR, Shetty A. Trends in the diagnosis of gestational diabetes mellitus. Scientifica (Cairo). 2016;2016:5489015. doi:10.1155/2016/5489015 
9. Herath H, Herath R, Wickremasinghe R. Gestational diabetes mellitus and risk of type 2 diabetes 10 years after the index pregnancy in Sri Lankan women-A community based retrospective cohort study. PLoS One. 2017;12(6):e0179647. doi:10.1371/journal.pone.0179647

10. Petersen JS, Dyrberg T, Damm P, Kuhl C, MolstedPedersen L, Buschard K. GAD65 autoantibodies in women with gestational or insulin dependent diabetes mellitus diagnosed during pregnancy. Diabetologia. 1996;39(11):1329-1333. doi:10.1007/s001250050578

11. Lapolla A, Fedele D, Pedini B, et al. Low frequency of autoantibodies to islet cell, glutamic acid decarboxylase, and second-islet antigen in patients with gestational diabetes mellitus: a follow-up study. Ann N Y Acad Sci. 2002;958:263-266. doi:10.1111/j.1749-6632.2002.tb02983.x

12. Kawasaki E. Type 1 diabetes and autoimmunity. Clin Pediatr Endocrinol. 2014;23(4):99-105. doi:10.1297/ cpe.23.99

13. Järvelä IY, Juutinen J, Koskela P, et al. Gestational diabetes identifies women at risk for permanent type 1 and type 2 diabetes in fertile age: predictive role of autoantibodies. Diabetes Care. 2006;29(3):607-612. doi:10.2337/ diacare.29.03.06.dc05-1118

14. de Leiva A, Mauricio D, Corcoy R. Diabetes-related autoantibodies and gestational diabetes. Diabetes Care. 2007;30 Suppl 2:S127-133. doi:10.2337/dc07-s204

15. Dereke J, Nilsson C, Landin-Olsson M, Hillman M. Prevalence of zinc transporter 8 antibodies in gestational diabetes mellitus. Diabet Med. 2012;29(12):e436-439. doi:10.1111/j.1464-5491.2012.03766.x

16. Damm P, Kuhl C, Buschard K, et al. Prevalence and predictive value of islet cell antibodies and insulin autoantibodies in women with gestational diabetes. Diabet
Med. 1994;11(6):558-563. doi:10.1111/j.1464-5491.1994. tb02035.x

17. Löbner K, Knopff A, Baumgarten A, et al. Predictors of postpartum diabetes in women with gestational diabetes mellitus. Diabetes. 2006;55(3):792-797. doi:10.2337/ diabetes.55.03.06.db05-0746

18. Bonsembiante B, Dalfra MG, Masin M, Gallo A, Lapolla A. Adult-onset type 1 diabetes and pregnancy: three case reports. Case Rep Med. 2013;2013:920861. doi:10.1155/2013/920861

19. Beischer NA, Wein P, Sheedy MT, Mackay IR, Rowley MJ, Zimmet P. Prevalence of antibodies to glutamic acid decarboxylase in women who have had gestational diabetes. Am J Obstet Gynecol. 1995;173(5):1563-1569. doi:10.1016/0002-9378(95)90650-9

20. Yu SH, Park S, Kim HS, et al. The prevalence of GAD antibodies in Korean women with gestational diabetes mellitus and their clinical characteristics during and after pregnancy. Diabetes Metab Res Rev. 2009;25(4):329-334. doi:10.1002/dmrr.963

21. Brahmkshatriya PP, Mehta AA, Saboo BD, Goyal RK. Characteristics and prevalence of latent autoimmune diabetes in adults (LADA). ISRN Pharmacol. 2012;2012:580202. doi:10.5402/2012/580202

22. Carpenter MW, Coustan DR. Criteria for screening tests for gestational diabetes. Am J Obstet Gynecol. 1982;144(7):768-773. doi:10.1016/0002-9378(82)90349-0

23. Classification and diagnosis of diabetes: standards of medical care in diabetes-2018. Diabetes Care. 2018;41(Suppl 1):S13-s27. doi:10.2337/dc18-S002

24. Bingley PJ. Clinical applications of diabetes antibody testing. J Clin Endocrinol Metab. 2010;95(1):25-33. doi:10.1210/jc.2009-1365 